\title{
Safer, deeper, faster: sprayed concrete — an integral component of development mining
}

\author{
M. Rispin UGC International, BASF Construction Chemicals, Switzerland \\ D. Howard Barminco Mining Contractors and Consultants, Australia
}

O.B. Kleven UGC International, BASF Construction Chemicals, Switzerland

K. Garshol NAFTA, BASF Construction Chemicals, United States of America

J. Gelson BASF Construction Chemicals, Australia

\begin{abstract}
It is a fact that underground mine workings are going deeper in the quest for ore reserves. This carries with it the need to develop workings under increasingly challenging environments with unprecedented economic and business pressures in the face of rising costs and high demand expectations.

While sprayed concrete (wet shotcrete) has established itself globally over the last 15 years as a preferred means of ground support, there are still significant opportunities for greater penetration from this versatile and effective ground support medium. It not only allows more rapid and safe development but further offers downstream benefits in the form of longevity, effectiveness and reduced rehabilitation requirements.
\end{abstract}

Stepwise improvements in the form of mix designs, admixtures and accelerators, equipment and expertise have yielded benefits in the form of early re-entry, logistics optimisation and effectiveness of application. Sprayed concrete has also proven itself as an attractive component of support systems in ductile environments.

This paper will cover the requirements of a successful sprayed concrete program from a holistic approach; reference a suitable case study, emphasising the contribution to safe and rapid development; and discuss current pertinent benefits and challenges for its use in the global mining industry in the 21st century.

\section{Introduction}

The challenges to mining companies going underground today are various, evolving and arguably increasing dramatically.

From a physical or geological standpoint, given that the resources resident in the Earth's crust are nonrenewable, attractive underground deposits today are either being newly found at greater depths through the use of advanced exploration techniques or are conversions from surface mining at a point where it has become less economical to extract through open-pit methods. Either way, mining companies are indicating a clear shift to a significantly greater portion of the world's mineral needs being met from underground mining methods.

Economically, as deposits go deeper, it becomes more of a challenge to generate returns from mining operations. The costs to put a new mine into operation before the production ore is reached and the first sales are generated have risen dramatically in recent years. Indeed, in times of steeply rising costs and of uncertainty of capital availability, the need for speed in development, both vertical and horizontal, becomes increasingly important.

A number of industry publications over the last year have focused on the development cycle and have included references from industry leaders to the effect that insufficient advancements have been made with respect to this aspect of the underground mining operation. When you break down the development cycle, it also becomes clear that most often it is the ground support component which consumes the most time. In order to improve development speed, the ground control component therefore offers the greatest opportunity. 
Technically, mining at depth typically brings with it more highly stressed ground, significantly higher temperature operating environments, logistical challenges to getting the ground support to the face, and a resultant greater "wear and tear" on the humans and machines doing the work.

From the standpoint of safety, which has never been more or less important, but rather paramount, great care must be taken in selecting a ground support system which can be applied safely and, more importantly, will perform in challenging environments not just in the short-term, but over time.

The clear benefits of sprayed concrete as an integral component of the development cycle speaks to all of these challenges:

- Logistical flexibility can decrease shaft time demands.

- Rapid application rates can bring in-cycle ground support application time down.

- A strong track record of safety in application.

- Typically requires less rehabilitation over mine life than bolt-and-screen.

- Provides a more hospitable environment for any ensuing production drilling and explosives charging.

As mines go deeper underground, sprayed concrete should be the first line of ground support type investigated. It has evolved over the last decade in particular to be employed in a great majority of new mines and especially where bulk mining methods are employed. Of course, a focused program must be designed and implemented properly and meet the ground control requirements. These topics are discussed in detail within this paper.

\section{Shotcrete or sprayed concrete essentials (wet mix)}

The holistic approach to quality shotcrete application in mining does not differ whether the mine practises multi heading operations (where the shotcrete operations may be somewhat less critical in terms of timing to the development process) as opposed to the mine that utilises single heading in-cycle shotcrete. The effects of any delays with in-cycle shotcreting will of course be more critical to the mine's productivity. However, the same principles apply to all successful shotcrete operations in mining.

\subsection{Shotcrete materials}

Shotcrete is essentially a high grade concrete, even though there are variations in such constituents as aggregate, slump or workability, logistical supply, testing, application technology, etc. Shotcrete, or sprayed concrete, is simply a way of efficiently casting concrete. The same concrete technology hence applies to shotcrete. The six main components of shotcrete are shown in Figure 1.

\subsection{Mix design}

Available aggregates at a mine may not be the optimum but wherever possible the mix design should be based on the well know aggregate grading curves common in the concrete industry. Shotcrete generally uses a top size of $10 \mathrm{~mm}$ aggregates and usually has greater fines, higher cement contents and lower water/binder ratios than cast-in-place concrete. Figure 2 is a typical combined aggregate grading curve for a shotcrete mix. 


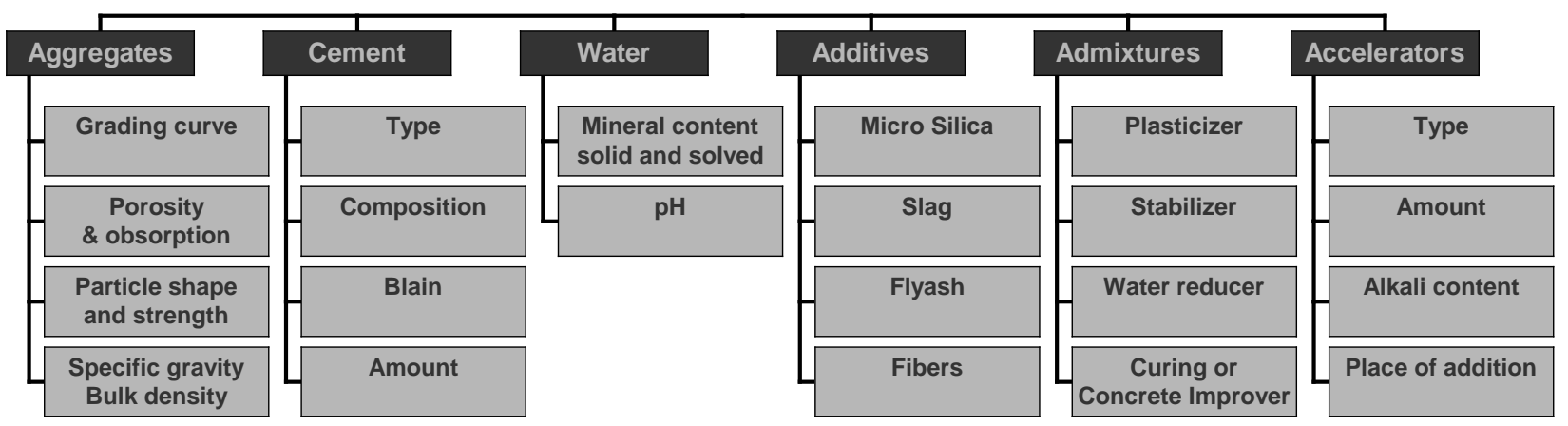

Figure 1 Main components of a wet shotcrete mix, showing variations within the main components

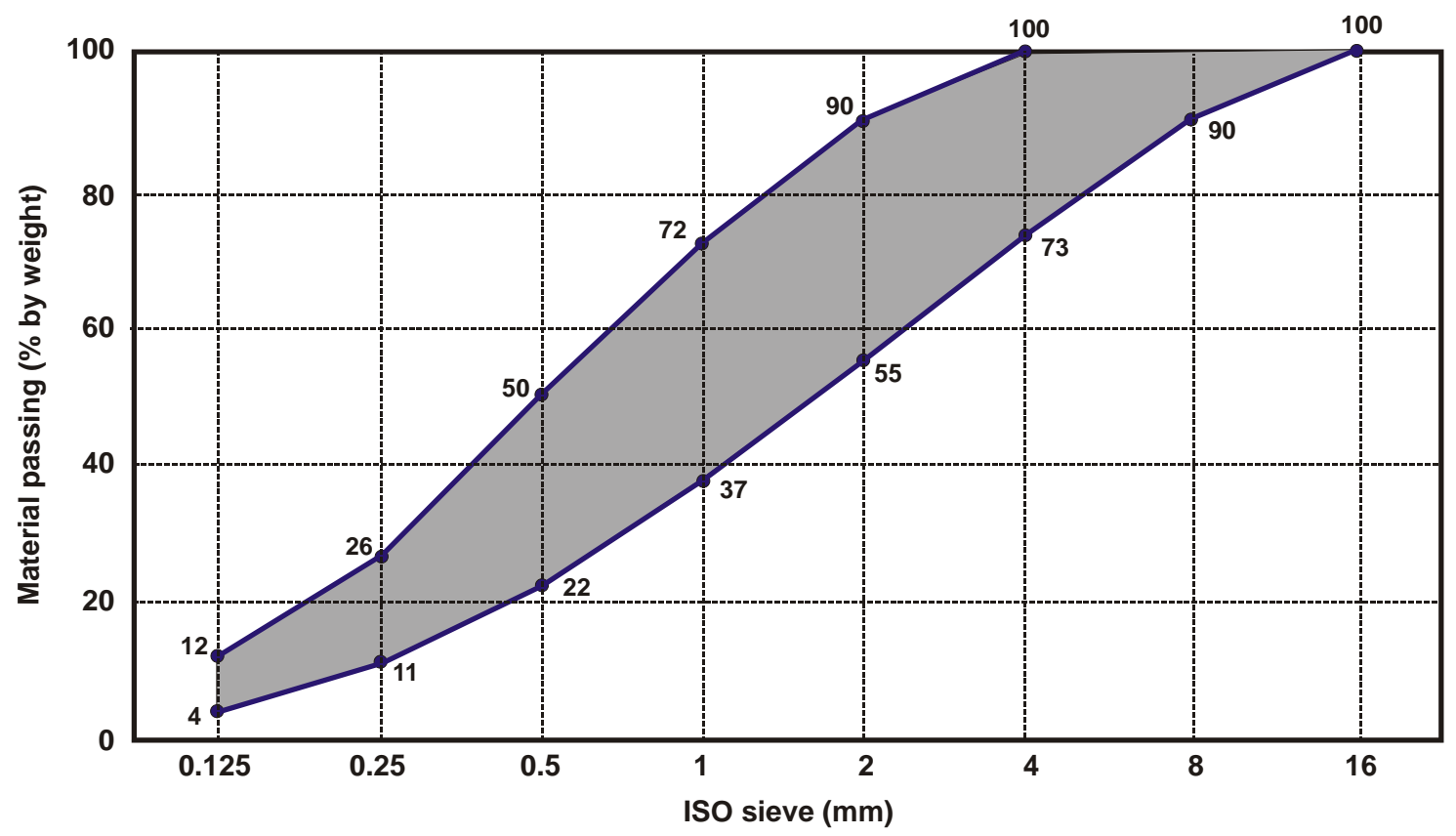

Figure 2 Typical combined aggregate grading curve

Inevitably, at many mine sites, the final mix design is a compromise based on available local aggregates and cement. However, wherever possible the optimisation of the mix design should be thoroughly encouraged.

\subsection{Cement}

Cement types vary, from ordinary portland cement (OPC) to blended cements that are increasingly being supplied. Blended cements utilise fly ash (or slag) to varying degrees and have certain advantages. Unfortunately, in the case of shotcrete, the cement reactivity with shotcrete accelerators tends to diminish. The quantity and particle size also have effects on the reactivity with accelerators used in shotcrete operations. The main factors are:

- Chemical composition (all cements vary).

- Fineness or Blaine of the cement (typically $350 \mathrm{~m}^{2} / \mathrm{kg}$ ).

- $\mathrm{C}^{3} \mathrm{~A}$ content (not less than 5\%).

- Age of cement (use of fresh cement is recommended where possible).

- Amount of cement in mix (normally around $400 \mathrm{~kg} / \mathrm{m}^{3}$ ). 


\section{$2.4 \quad$ Water}

Water should be free from oils and other contaminants. The $\mathrm{pH}$ and level of both dissolved and suspended solids should be checked. In practice the water/cement or water/binder ratio is normally the key factor in a good mix design (under no circumstances should it be above 0.42 ) and has large effects on reactivity speed, final strengths and durability of the placed shotcrete. In cooler mines, heating the mix water may be necessary to assist the speed of shotcrete set.

\subsection{Additives}

These typically include microsilica (silica fume) either in powder or liquid form. Often used to assist in grading and produce a more pumpable and stickier shotcrete mix, silica fume also assists in filling the pore spaces in the shotcrete matrix and produces a less porous, more durable, higher strength shotcrete. The pozzolanic effects of using silica fume really only affects the later strength and curing of shotcrete after 28 days. There are other fine fillers that are being used in some shotcrete markets (i.e. Australia) such as carbonates to fill the pore spaces in the shotcrete matrix and enhance "stickability".

\subsection{Fibres}

The post crack load bearing capacity of fibre reinforced shotcrete is typically referred to as toughness. Steel fibres were the most common type of fibre used in mines; however, in the last five years high quality polypropylene structural fibres (macro synthetic fibres) have progressively taken over this market. Steel does exhibit superior load bearing capacity at small deflections and is still favoured in civil tunnels, or where it is thought to be more suitable in specific mines. However, in large deflections the cost effectiveness of steel diminishes in favour of synthetic. There are some hybrid combinations also being used.

\subsection{Admixtures}

High quality shotcrete with low water/binder ratios and high workability and pumpability could not be produced or maintained without the use of chemical admixtures. Admixtures are used to reduce the water content in the mix and increase the workability (measured by slump) and slump retention of the shotcrete mix. Today's high range plasticisers give about a $45 \%$ water reduction while maintaining the required workability, or slump. The latest generation of polycarboxylate hyperplasticisers have the ability to greatly reduce the water content in the mix and still provide excellent workability and slump retention for hours.

\section{$2.8 \quad$ Hydration control}

When cement is mixed with water, the hydration process immediately starts. This is the normal chemical/curing/hardening effect of cement that then binds or glues all the aggregates in the shotcrete mix. Hydration control admixtures completely stop this hydration process. In the authors' opinion, this control has probably had the biggest effect on the wide scale adoption and use of shotcrete as a means of ground support in mines. The fact that the setting of shotcrete can actually be controlled has unique advantages. Long logistics transportation times, the risk of machine breakdowns, or loss of air or other services means that with the minor addition of the hydration control admixture to a shotcrete mix, complete reliability of receiving "fresh" shotcrete to the operation is virtually guaranteed. The dose rate that is commonly used in mines provides around four to six hours of protection from hydration. However, the dose rate can be increased to effectively put the shotcrete "to sleep" for up to 72 hours.

\subsection{Accelerators}

The "need for speed" is paramount in high speed shotcrete applications as efficient mining operations, and particularly in-cycle operations, cannot wait for the shotcrete to naturally hydrate and harden to a desired strength. The accelerator is also needed to provide instant slump loss, allowing the shotcrete layer to be built up to an acceptable lining thickness without sloughing off the back or walls. The industry has moved largely away (with exceptions in only certain jurisdictions) from outdated technologies and now uses the much safer alkali free accelerators. The accelerator which is added at the nozzle immediately knocks out any hydration control admixture and acts on the cement particles to kick start the hydration process. Adding the accelerator into the air stream just prior to entering the nozzle and the shotcrete stream provides optimum mixing and 
penetration (Figure 3). Too low a slump of shotcrete also often causes incomplete mixing of the accelerator and shotcrete, resulting in the "hot and cold" spots on the wall. Slumps of around 150-180 mm is the industry norm. However, in Europe higher slumps of 180-220 mm are often preferred to not only give better accelerator mixing but more complete filling of shotcrete pump cylinders to reduce detrimental pulsation effects. The debate about ideal slump will no doubt continue, as common feeling among contractors and the like is that higher slump requires higher dose rates of accelerator to bring about the desired instant slump loss. Operator experience and the spray action are probably the key factors in maintaining normal dose rates of accelerators with high slump mixes. The authors' caution against low workability mixes (due to less-than-ideal pump cylinder filling) as these have a tendency to exacerbate pulsation which can, in turn, lead to layering of the in situ shotcrete.

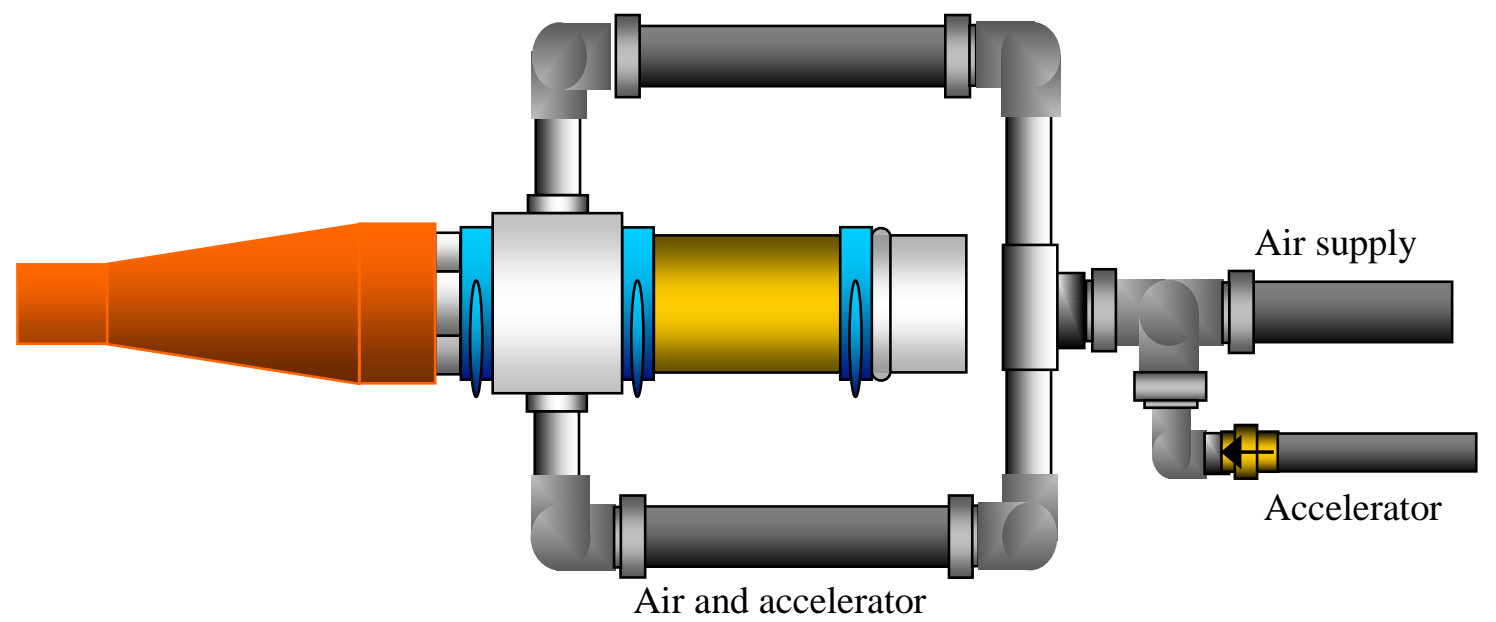

Figure 3 Accelerator dosage into air supply, with twin air inlets to nozzle

The latest alkali free accelerators (AFAs) typically provide faster set times but in every application site specific trials should be done to check out the cement/accelerator reaction times and subsequent strength development over time. Fast initial set can be accompanied by very slow strength development over the next 24 hours, which can create serious inadequacies with respect to the ground support requirements and hence real safety issues. One is advised to select a state-of-the-art AFA which gives a balanced strength development, i.e. a balance between high early strength and constant ongoing strength development (avoiding any "sleep" periods). This can be determined by monitoring strength development, especially during and after three to six hours of age. Normal accelerator dose rates are between four to eight per cent in practice.

\subsection{Bond strength}

The need to have good adhesion or bond to the rock substrate is paramount to good shotcrete operations. Good substrate preparation is therefore essential. High pressure water blasting, or hydroscaling, is now widely practised. Minimum practice should be water blasting using assisted air pressure on the shotcrete machine to effectively remove all loose dust and dirt. Larger rocks, if loose, will need careful mechanical scaling.

\subsection{Equipment}

The equipment selection needs to be holistically approached - this includes the batch plant, the supply trucks and the actual shotcreting machine. The whole setup has to be complementary, balanced and able to cope with the planned volumes of shotcrete for the mine. If the depth or logistics in the mine imposes severe problems with truck supply from the surface, a vertical slick line or borehole may provide the solution.

All shotcrete equipment needs to be robust for mining, have suitable reach (spraying boom), minimum pulsation when spraying (unlike a standard concrete pump), be capable of spraying shotcrete at the desired output, have integrated dosing facilities for the applied accelerator, and be safe and reliable. The shotcrete 
machine has to be able to apply shotcrete remotely to ensure the operator is in a safe working position and not exposed to either unsupported ground or freshly shotcreted ground. The latest development in shotcrete equipment is the use of automated, remote application machines which have the potential to eliminate the industry current safety and quality issues.

\subsection{Operators and training}

The best shotcrete mix is only as good as the shotcrete machine and the operator who applies it underground. The recent boom in mining and the inherent growth of shotcrete in mining has effectively led to a shortfall in experienced shotcrete operators. Most large companies that practice shotcrete have training programs in place and rely on on-the-job training with an experienced applicator.

\subsection{Holistic management approach to shotcrete}

The importance, control and quality use of shotcrete must be reinforced at all levels of management right through the operations to the nozzle-man at the face. This is an integral part of the ground support regime at the mine and should be treated as such, with all the safety ramifications and production efficiencies at stake. Mine management support is essential to ensure this message is clearly understood by all. The many aspects of a quality program can be seen in Figure 4. One could write huge dissertations on every facet in this diagram, but that is outside this brief review. The main principle is to see that for successful shotcrete, operations in a mine require all the areas in the "wet shotcrete circle" to be effective and working in unison. One weak link will have detrimental effects. In safe and rapid developments using shotcrete, all these factors, such as specifications, mix design, testing, training, equipment, logistics, application, quality control, and commitment must be very well addressed.

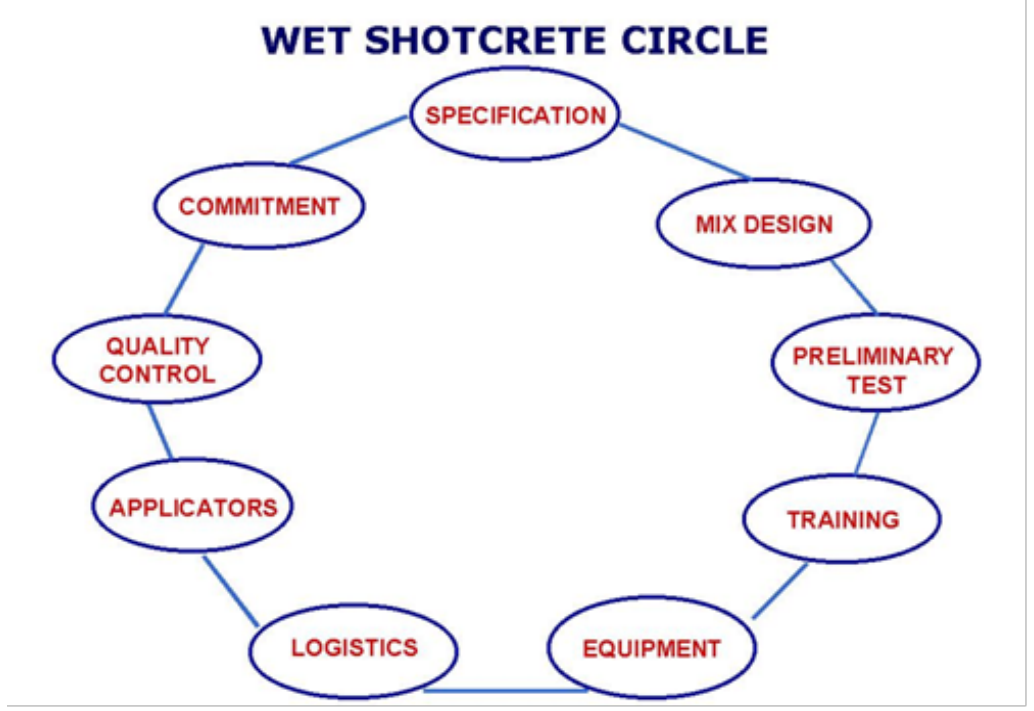

Figure 4 The holistic approach for sustainable high quality shotcrete operations

\section{$3 \quad$ Re-entry into a shotcreted heading}

One of the barriers to greater penetration of wet-mix shotcrete into mines other than multiple development heading mines, is being overcome with early re-entry times. Through a combination of state-of-the-art admixture technology, proper holistic mix designs and expert application, two hour re-entry times are now regularly being achieved (Knight et al., 2006). This is a far cry from the typical eight hour waiting times prevalent in the industry beforehand.

\subsection{Re-entry: present status}

Shotcrete lining thicknesses in mines vary depending on the required ground support regime required and are determined by the geotechnical engineers. In practice, shotcrete lining thicknesses in mines typically vary 
from 50-100 mm. The adoption of fibre reinforced shotcrete (FRS) linings in mines compared to mesh has many advantages in terms of safety and longevity.

The need for rapid development rates has in recent years seen the increase of in-cycle shotcreting, where the shotcreted roadway lining is an integral part of the development cycle. The normal process of drill and blast, mucking out, fibre shotcrete application and then rock reinforcement via bolting is now common practice.

Early re-entry times are a key factor and a great deal of work is ongoing worldwide (Bernard, 2007) into establishing parameters to decide when it is safe for operators to re-enter the freshly shotcreted heading.

Recent studies and tests have shown that in the early strength development of a shotcrete lining the predicted primary mode of failure is by punching shear, where a wedge can punch through the lining by shear on the lining perimeter. Hence, shear strength is a determining factor. However, as the shotcrete cures and increases in compressive strength (UCS), the mode of failure changes to delamination and flexural failure. Unfortunately shear strength is difficult to measure in situ; however, recent work is showing a relationship of shear strength to UCS which is far more easily measured.

In practice, the generally adopted rule of thumb in many mines in Australia of a minimum 1 MPa UCS in the early age strength of the shotcrete lining prior to re-entry is used, although this is a local site specific gauge and some mines are much more conservative. It also should be noted that even upon re-entry, the next cycle of drilling and bolting is typically done remotely with the drilling jumbo, and operators do not expose themselves unduly until the heading is fully bolted.

\subsubsection{Early bolting times}

Some ground support requirements call for bolting to be carried out through the shotcrete prior to the development cycle re-commencing, as opposed to being able to carry out campaign bolting off-cycle. In this case, the waiting time prior to "re-entry" is limited to when a mechanised bolting operation can be carried out without degrading the fresh shotcrete.

With proper mix design, use of a quality alkali-free accelerator and well maintained equipment and educated applicators, earlier re-entry is definitely achievable. As proven in a 2006 trial at Kidd Creek Mine, the shotcrete liner was able to be drilled as early as 30 minutes after application when the shotcrete had achieved a uniaxial compressive strength of 0.8 MPa. Even at this early age there was no deterioration or wash out of the shotcrete liner in the area where the bolter was drilling (Knight et al., 2006).

\subsection{Early age strength testing of shotcrete}

The critical factors from a safety and efficiency point of view are:

- Time to reach the desired UCS laid down at the mine.

- Accuracy in the measurement of UCS of the shotcrete lining in situ.

Many methods and instruments have been, and currently are, used to measure this early strength development of shotcrete in mines. The distinction needs to be made between "early set" and early strength of shotcrete. As with normal concrete, the setting of shotcrete should be considered between $0-0.5 \mathrm{MPa}$. Early age strength development should be considered above $0.5 \mathrm{MPa}$ and recorded to 24 hours. Typically the standard method of measuring shotcrete strength is by taking test cylinders from the concrete mixer and/or cores from sprayed panels or the roadway. These are tested at 28 days. These methods are obviously not applicable to measure early strengths of shotcrete from initial spraying over the first 4-24 hours. Hence a range of commonly used instruments to measure early strength development are detailed in this section.

\subsubsection{Soil penetrometer; range 0-1.4 MPa}

This instrument is easy to use, and provides an indirect measurement of UCS, however work done in Australia (Clements, 2004) and others also showed huge failings in the results from this type of instrument. Typically the instrument reads between $50-75 \%$ too high. Hence, the safety failings of relying on such a unit for determining safe early re-entry times are very real and apparent. The unit is easy to use and very portable, but should only be used for comparison trials, testing would be required to determine the actual reading onsite. Figures 5-8 show the various testing instruments presently used in mining. 


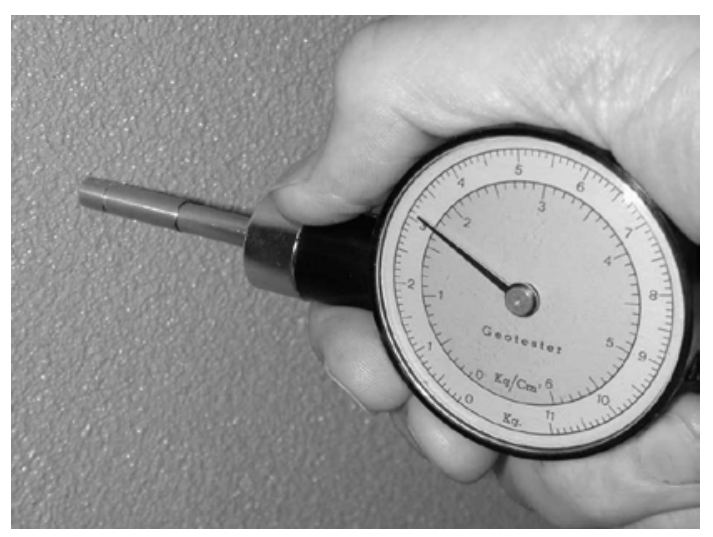

Figure 5 Soil penetrometer - comparison testing only

\subsubsection{Needle penetrometer; range 0-1 MPa}

Testing work has shown that this instrument, although using an indirect method of calibrating the UCS, is reasonable. Good correlation between beam tests and the needle penetrometer provides confidence that the UCS measured is reasonably accurate. The unit is easy to use and readily portable but does require care in using and also requires the use of a calibration chart.

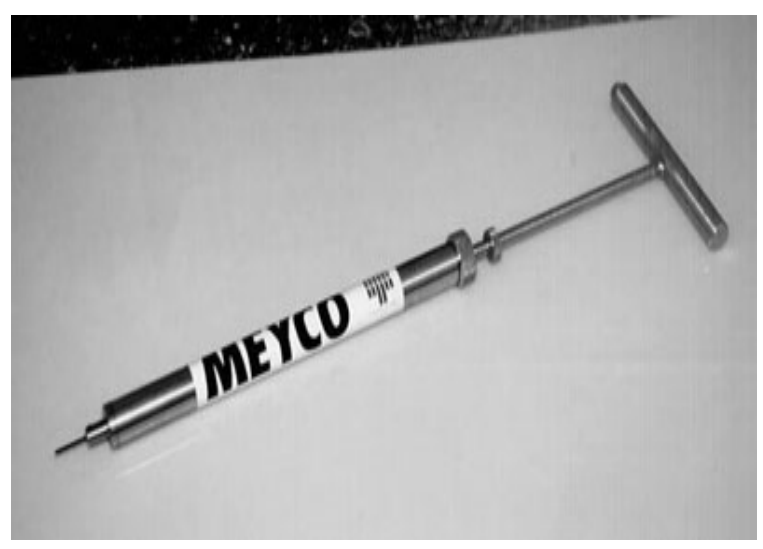

\section{Figure 6 Needle penetrometer}

\subsubsection{Beam tester; range $0.5-10 \mathrm{MPa}$}

This is an accurate direct measurement of UCS of the shotcrete. Sprayed moulds are taken which can then be tested above a minimum strength of $0.3 \mathrm{MPa}$ (this can be assessed by taking complementary needle penetrometer readings) but typically above $0.5 \mathrm{MPa}$.

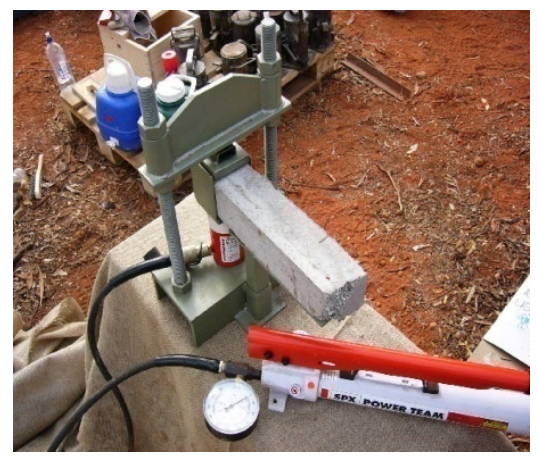

Figure 7 Beam tester with sample beam 


\subsubsection{Hilti nail gun/pull test; range 2-10 MPa}

This method is not commonly used in mines but moreso in civil tunnelling. The unit is indirect and relies on firing a nail into the hardened shotcrete and then recording the pull out force to remove it. Using this force and the embedment of the nail in the shotcrete a UCS is calibrated. The nail gun is of restricted value in the very early strength development (below $2 \mathrm{MPa}$ ) and also requires a certificate of competency to use underground in some jurisdictions.
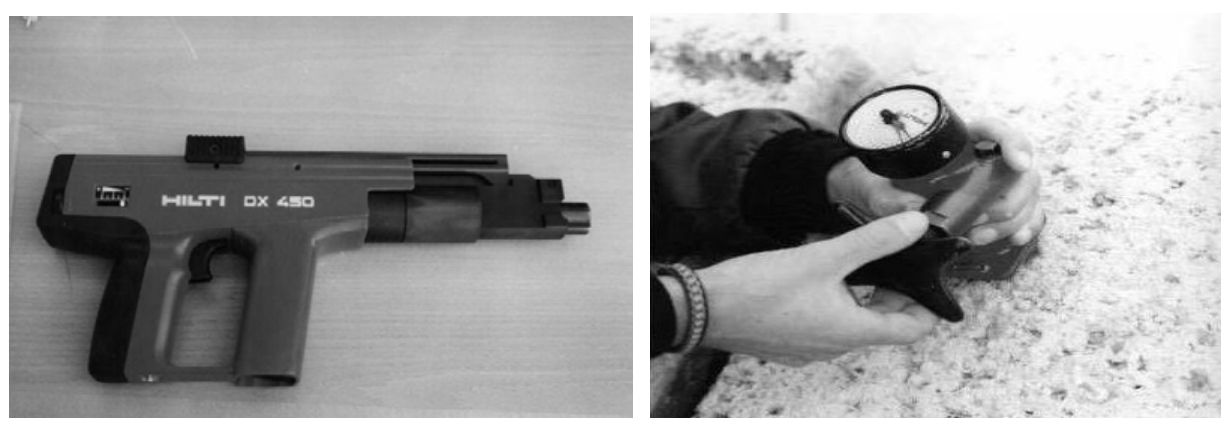

Figure 8 Hilti nail gun

\subsubsection{Drill cores; range $+10 \mathrm{MPa}$}

Used for post 24 hours strengths and not applicable in the early hours.

\section{$4 \quad$ Sprayed concrete as part of a ductile support system}

In deep level mining we can safely assume that high rock stresses will be present and as the mining cycle progresses, these stresses may even be concentrated to higher levels in local areas.

How these high stresses will influence the behaviour of rock stability and rock support systems will very much depend on the characteristics of the rock, like uniaxial compressive strength, degree and character of jointing, etc.

What typically leads to the most serious problems underground is when the radial convergence of the opening goes beyond certain limits. The rock surrounding the opening will typically start breaking up to a progressively larger depth with increasing convergence (the plastic zone of the Fenner-Pacher curve Figure 9) as measured from the excavation contour. At the same time, installed reinforcement, i.e. bolts, may become overloaded or too short for the evolving ground situation and the applied shotcrete shell may start suffering different kinds of failures (buckling and debonding, shear failures and compressive failures by crushing).

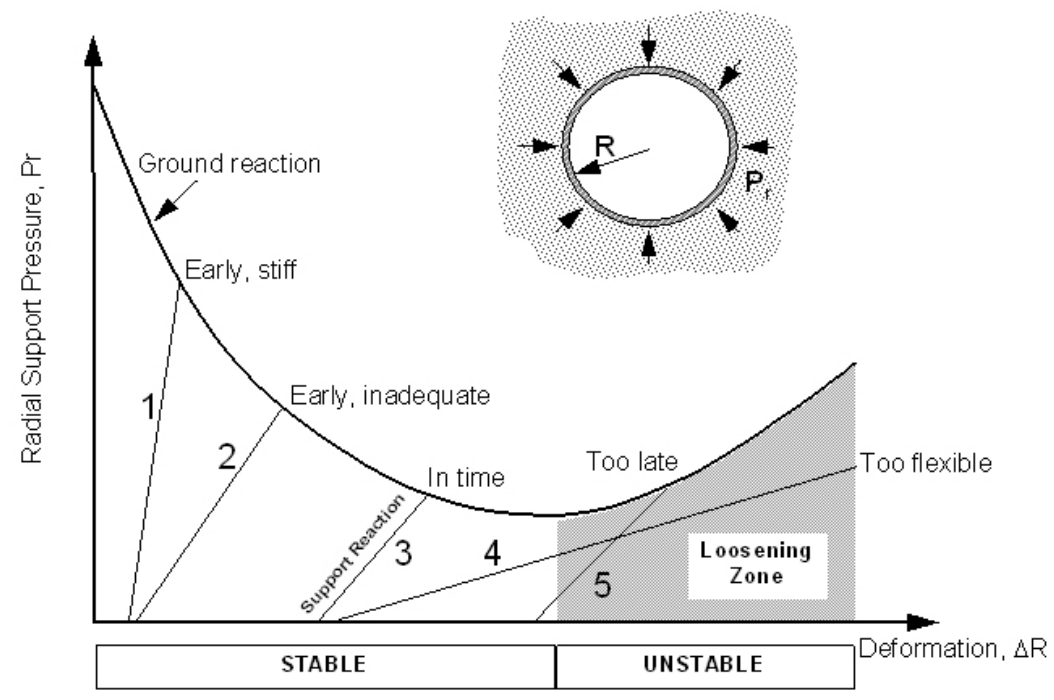

Figure 9 Fenner-Pacher curve illustrating ground support interaction 
Shotcrete is a relatively stiff and brittle material in such cases and even if we add reinforcement in the form of steel or synthetic fibres, the basic parameters of the concrete do not change.

Whether the high rock stress problems lead to squeezing, strain bursting or rockbursting, the only realistic way to deal with such cases involves balancing the support elements to each other and to the behaviour of the rock. We are therefore talking about a rock support system more than rock support elements and the primary target is to accept and allow deformations without losing the support system integrity. To illustrate the point, some examples may be useful.

Fully grouted bolts (set in cement or resin) do work very well in many situations, but when the load and deformation goes beyond the failure elongation of a very short stub of the bolt steel on both sides of a moving joint, it will fail. The full load will then be transferred to other installed support elements and they may in turn also fail.

An end-anchored bolt (or any kind of yielding bolt) will allow a lot more deformation before failure, but if this deformation level causes the rock in the tunnel contour to break up and fall out between the bolts, the bearing plates will ultimately be hanging in the air and the bolts are rendered useless.

Shotcrete is frequently used in combination with bolts to prevent this from happening and it works best when the bearing plate is placed on the shotcrete surface. This, of course, implies that the shotcrete is applied first in the development cycle as initial ground support, followed by the bolting operation.

However, if the radial convergence causes more than one per cent compressive strain in the shotcrete shell, it will fail. Eventually, so much damage can occur that the shotcrete shell does not work anymore. Because of this, it is important to limit the strain level, which can only be achieved by adopting special measures.

In civil tunnelling through the Alps in Europe and elsewhere, subdividing the shotcrete shell into limited length segments by leaving open (not sprayed) longitudinal slots has worked very well. Such slots may be equipped with compressible load elements that will provide a constant closure resistance over a distance of say $300-500 \mathrm{~mm}$. With four longitudinal slots, this would allow between one and two metres of tunnel contour shortening caused by radial convergence, still maintaining the integrity of the shotcrete shell.

Shotcrete can fail in tension or shear as well as in compression. The tensile failure energy of shotcrete, even when reinforced, is limited and especially in the case of rockbursting does not contribute much to the necessary total energy dissipation capacity of the support system. The yielding holding elements (bolts and anchors) have to take most of the released bursting energy that is not dissipated by the rock dilation.

The task of the shotcrete shell is to contain the surface, prevent unravelling and transfer load from the bolt bearing plates (so they do not end up hanging in the air). To be able to do this, it is important that the shotcrete has a high peak tensile strength (to avoid breaking up into too many small areas) and then after the initial cracks are formed, that it allows a long way of deformation with residual resistance (to keep the pieces together).

To achieve this, reinforcement of the shotcrete matrix with state-of-the-art macrosynthetic fibres provides comparable if not better performance than steel fibre reinforcement. Reinforcement with wire mesh may also provide a high performance level but poses significant challenges in application so as to seriously limit its attractiveness in this context.

\section{Safety benefits}

\subsection{Safety in application}

Sprayed concrete has performed remarkably well from a safety standpoint during application over the years. The process with modern equipment and trained operators means that humans are never exposed to working under unsupported ground, are kept away from the development face and roof, are kept at a relatively safe distance from the application operation, and frequently operate from inside an enclosed cab. In fact, the authors are not aware of any incident with respect to sprayed concrete in mining the world over, where an individual has been injured with respect to either a fall of ground or the sprayed concrete itself (fallout) during application. 


\subsection{Safety in performance}

It is well known that a vast majority of injuries and fatalities in underground mining are the result of falls of ground, often smaller pieces of rock rather than catastrophic failures. These have often occurred in environments where bolting alone has been used, allowing for the fallout of significantly sized pieces between the bolt patterns.

Sprayed concrete eliminates this issue with the support of the pieces between the bolts and also performs consistently with the ground support philosophy that, with only a few exceptions, nothing supports the ground better than the ground itself and therefore by holding up the smaller pieces, the larger blocks are successively held in place and the overall excavation is more stable.

Sprayed concrete (with bolts) also provides a more active ground support system than mesh-and-bolts and prevents the "relaxation" typically experienced before this system truly becomes effective. It also eliminates the nuisance falls of small pieces from between the mesh openings. Furthermore, during any ensuing production drilling, the ground is held effectively in place.

\section{Representative case study - Marvel Loch mine, Western Australia}

The use of high quality shotcrete and modern application techniques has greatly increased the safety and efficiency of shotcrete operations in mines. Faster re-entry times have enabled in-cycle shotcrete operations to be a positive inclusion as part of the development cycle for underground roadways. An example of how the use of shotcrete as part of the in-cycle ground support regime has benefitted the safety and efficiency of mining operations is now outlined.

A good example of this is at the Marvel Loch mine. Marvel Loch is located $30 \mathrm{~km}$ south of Southern Cross in Western Australia. Marvel Loch is a gold mine with mineralisation that extends over a $1.3 \mathrm{~km}$ strike length and has been identified to depths of over $700 \mathrm{~m}$ below surface. The orebody comprises multiple lodes. Those currently being mined include Sherwood and Undaunted at the north; Exhibition at the centre; and East and New at the south. Mining methods include up hole benching and open stoping with rock fill, where necessary. The mine is owned by St Barbara's Ltd and is mined by Barminco Ltd.

Ore production from Marvel Loch underground mine for the 2008 financial year was 900,000 $t$ at an average grade of $3.7 \mathrm{~g} / \mathrm{t}$.

With the introduction of shotcrete back in February 2007, the mine has been able to increase the average jumbo development metreage rate significantly, utilising a $1 \mathrm{MPa}$ strength requirement of shotcrete for reentry of the jumbo within one hour. The monthly jumbo rate has increased (Figure 10):

- Apr 06 - May 07: 3 jumbos avg $\mathrm{m}$ rate $=142 \mathrm{~m} / \mathrm{jumbo}$.

- Jun $07-$ Sep 07: 2 jumbos avg $\mathrm{m}$ rate $=216 \mathrm{~m} / \mathrm{jumbo}$.

- Oct $07-$ present: 1 jumbo avg $\mathrm{m}$ rate $=372 \mathrm{~m}$.

Since the shotcreters are fully utilised by hydroscaling the headings, doing all surface support and all rehabilitation work within the mine, this has meant the jumbos are fully utilised boring and bolting. It has also been noticed that there has been a significant reduction on the maintenance costs for the jumbos. 


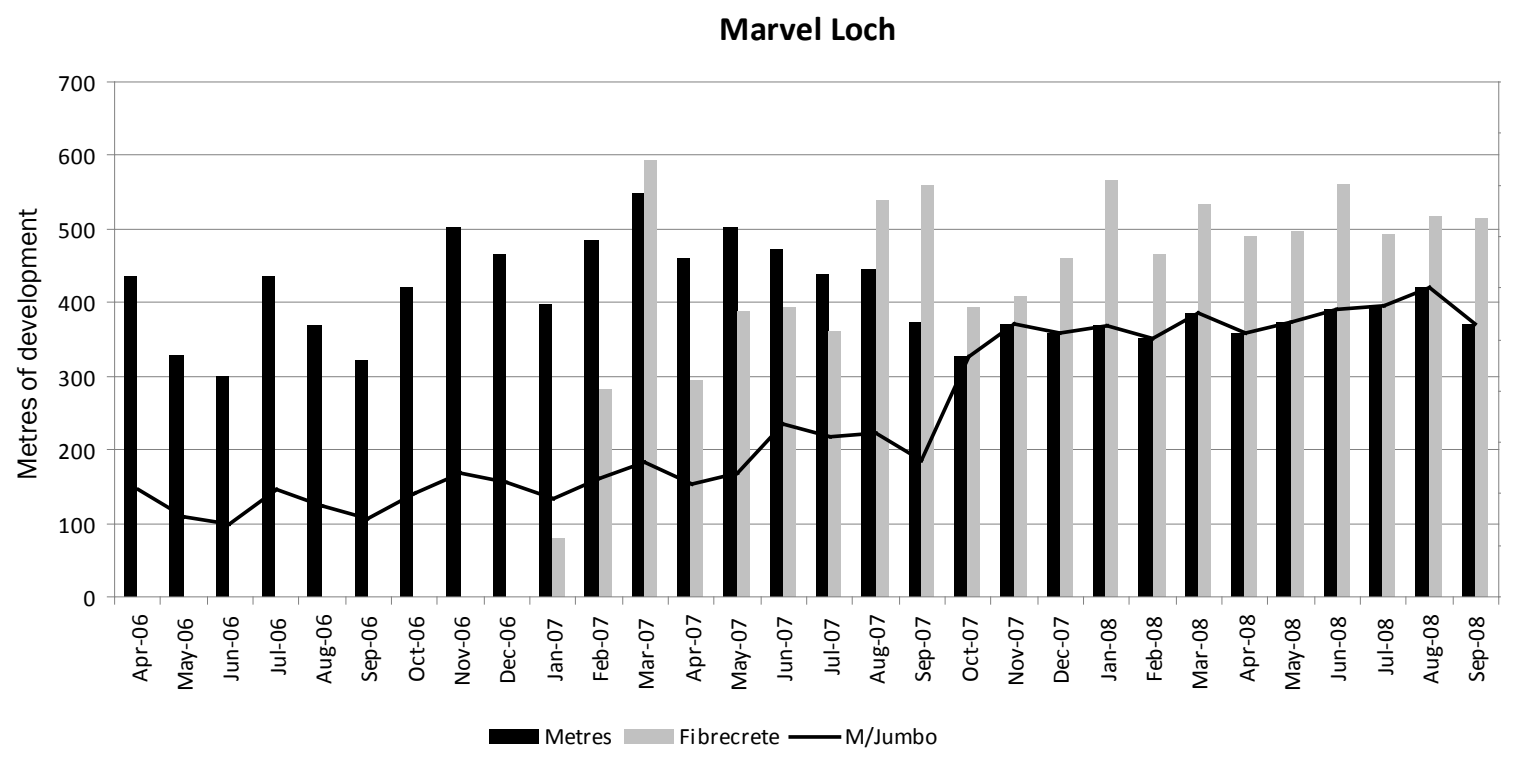

Figure 10 Showing the increase in jumbo metres obtained with in-cycle shotcreting

The net result after a substantial increase in performance by the drilling jumbos, even with a reduced number of rigs, has shown a reduction in maintenance costs and reduced incidences of safety issues.

\section{References}

Bernard, E.S. (2007) Early-age load resistance of fibre reinforced shotcrete linings, Tunnelling and Underground Space Technology, 23, pp. 451-460.

Clements, M.J.K. (2004) Comparison of methods for the early age strength testing of shotcrete, Proceedings of 2nd International Conference on Engineering Developments in Shotcrete, E.S. Bernard (ed), Cairns, Australia, Taylor and Francis Group, London, pp. 81-89.

Knight, B., Rispin, M. and Clegg, I. (2006) Wet-Mix Shotcrete as a Material, Process, and Ground Control Component of a 21st Century Underground Mining Operation; Proceedings of the 10th International Conference Shotcrete for Underground Support, D.R. Morgan and H.W. Parker (eds), Whistler, Canada, Reston, VA: ASCE/ECI, pp. 298-306. 